\title{
Enfoque Estratégico del Turismo Comunitario para el Fortalecimiento del Desarrollo Local
}

\author{
Strategic approach to community tourism to strengthen local development \\ Cristina Flores-Amador ${ }^{a}$, Ernesto Bolaños-Rodríguez $^{b}$
}

\begin{abstract}
:
The present map tries to show the different elements used in a theoretical methodological model from the community and the social economy. Tourism has been considered as an engine of impacts that local development, therefore, within its various modalities, it becomes a dyna Dynamics of unlimited products that manages to create indispensable changes in rural areas, viewing tourism as a broad way of social order of progress where the endogenous organization has models with self-management orientation for the use and exploitation of its resources, based on respect for its worldview that demands strategic initiatives to incentivize investments as a primary factor to forge quality conditions and competitiveness, from the systemic multidisciplinary articulation.
\end{abstract}

Keywords:

Tourism, Community, Local Development, Social Economy

\section{Resumen:}

El presente mapa pretende mostrar los diferentes elementos empleados en un modelo teórico metodológico desde la comunalidad y la economía social el turismo se ha considerado como motor de impactos que favorecen el desarrollo local, por lo que, dentro de sus diversas modalidades se convierte en una dinámica de productos ilimitados que logra crear cambios indispensables en las zonas rurales, visualizando al turismo como una amplia vía de orden social de progreso donde la organización endógena tiene modelos con orientación de autogestión para el uso y aprovechamiento de sus recursos, a partir del respeto de su cosmovisión que dema nda iniciativas estratégicas para incentivar las inversiones como factor primordial para forjar condiciones de calidad y competitividad, desde la articulación multidisciplinaria sistémica.

Palabras Clave:

Turismo, Comunalidad, Desarrollo Local, Economía Social

\section{Introducción}

El presente mapa tiene la intención de abordar diferentes elementos de un modelo teórico metodológico que muestre la situación que prevalece en el campo mexicano que experimenta una realidad de crisis económica productiva, circunstancial y sociocultural, que ha marcado la pobreza rural, lo cual proyecta un escenario de abandono y atraso en el entorno rural, dentro del cual, el segmento campesino representa un papel marginal en los términos de la economía globalizada, en el desarrollo y el libre mercado. Derivado de estos contextos desfavorables, el turismo se ha tornado como motor generador de empleos, dentro de sus diversas modalidades transformando a la actividad turística en un producto ilimitado que logra concebir cambios precisamente en las zonas rurales que demandan satisfacer amplias necesidades, priorizando las

\footnotetext{
a Escuela Superior de Tizayuca, Universidad Autónoma del Estado de Hidalgo, México, Km. 2.5. Carretera Federal Tizayuca - Pachuca, 43802, Tizayuca, Hidalgo.https://orcid.org/0000-0001-8122-3094, email: cristinafloresamador@hotmail.com

b Escuela Superior de Tizayuca, Universidad Autónoma del Estado de Hidalgo, México, Km. 2.5. Carretera Federal Tizayuca - Pachuca, 43802, Tizayuca, Hidalgo. https://orcid.org/0000-0002-1432-7720, email: bola7112@yahoo.com.mx
} 
expectativas de las comu nidades receptoras, que buscan fortalecer y mejorar sus condiciones de vida, lo que representa una sinergia entre localidad y turismo, donde el desarrollo local es un resultado de ambas, aminorando la marcada vulnerabilidad de localidades con potencial turístico.

Es entonces, que debido a la aguda exclusión que los campesinos e indígenas han enfrentado al ver minadas su con diciones de vida, su rge la imperiosa necesidad de afrontar un cambio radical, que modifique ese panorama, es por elloque, recientemente por medio de la actividad turística se ha avanzado en la dinámica productiva local, posicionándose como una propuesta socioeconómica, de innovación e implementación que posibilita optimizar las condiciones de vida de las comunidades rurales, como destinos turísticos, modificando sus principales actividades de campesinos a prestadores de servicios turísticos, obteniendo beneficios, como, empleos, diversificación de la oferta, incremento en el entorno de oportunidades, sumando acciones para el desarrollo local, donde el turismo tiene una participación medular como eje central, para desempeñar trabajos encaminados a detonar y aprovechar los recursos de la localidad receptora, en un esquema colaborativo para conseguir mayor competitividad de éstas zonas, y por lo tanto aportar mayores coyunturas transdisciplinarias y sistémicas que se vean enfocadas hacia cambios comunes, donde las personas que se desempeñan como prestadores de servicios turísticos son el principal actor productivo de todo este sistema productivos.

Es así, que ya en la actualidad el turismo desde sus numerosas modalidades se desarrolla como una labor productiva que fortalece la economía, convirtiéndoloen una sinergia; entre localidad y tu rismo, don de el desarrollo local es un resultado entre ambas, propiciando la diversificación de la oferta y calidad de vida,donde en la práctica del turismo se emplean estrategias de planificación holísticas encaminadas a generar modelos teóricos metodológicos sustentados en la perspectiva de responsabilidad social, mediante estructuras que detonen enfoques sistémicos para poder dar una respuesta a problemas donde existen componentes que atiendan un desarrollo integral socioeconómico.

En ese sentido, se puede mencionar que después de la hegemonía de los enfoques de desarrollo local exógeno; desde arriba y desde fuera, se han configurado a partir del turismo otras orientaciones de desarrollo de abajo hacia arriba y desde dentro hacia afuera, que han prosperado para la configuración del nuevo desarrollo local o endógeno. Aquí puede asumirse que el turismo enmarcado en el desarrollo local con visión comunitaria y solidaria es, una alternativa que se interesa por incluir a las personas, esta perspectiva ha dado forma $y$ funcionamiento al turismo con desarrollo local desde el interior de las propias comunidades rurales, entendido como estrategia comunitaria, distribuyendo el capital generado entre las familias, para dar a sus integrantes los beneficios que la actividad que conciben (Flores2014).

Por otra parte, una de las ventajas de estudiar el turismo a partir de la economía social y la intención de contribuir con el desarrollo local, es exponer que se tienen opciones económicas locales, con las que se unifica los esfuerzos comunitarios, en específico para las comunidades que demandan y buscan la autosuficiencia económica recurriendo a iniciativas que promueven, desde las propias zonas rurales, apoyado desde un enfoque más amplio para mejorar su vida. A partir de este contexto, la economía social desde lo populary comu nitario puede dar lugar a un sistema de economía del trabajo, capaz de representar y dar fuerza efectiva a los proyectos de calidad de vida en una sociedad más igualitaria, más ju sta y autodeterminada, es entonces que, la economía popular busca otras formas de hacer efectivas las capacidades de las personas, compitiendo o asociándose para acceder a los medios y condiciones de vida a través del trabajo comunitario, de la producción simple de mercancías en emprendimientos individuales, familiares o cooperativas, de las redes de coalición (Coraggio, 2003). 


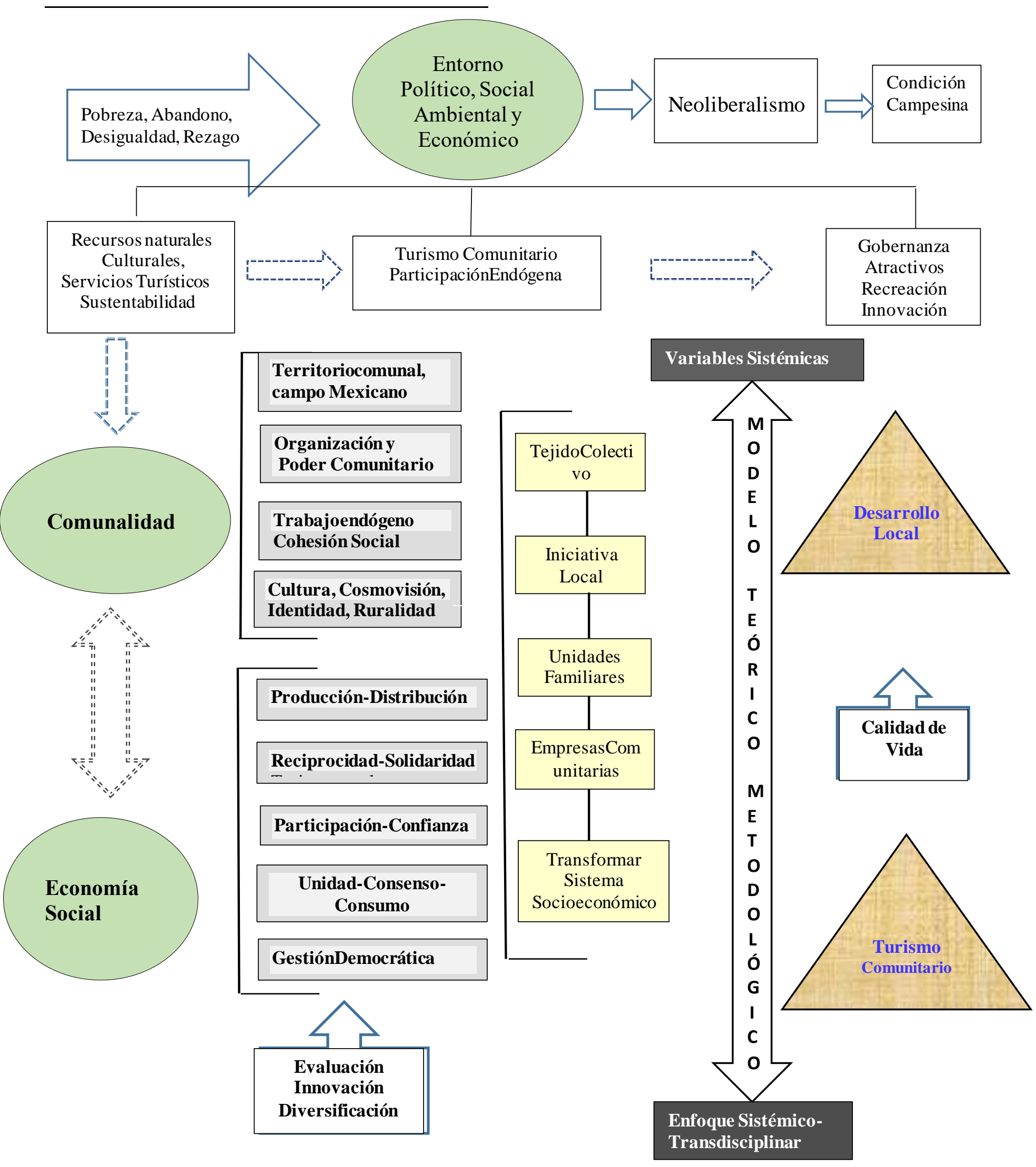


Lo notable en esta situación, es que los beneficios obtenidos, sean efecto de la ordenada y voluntaria mediación de los pobladores, aunado a la detallada observancia de responsabilidades y cargos asignados por los comuneros en convenios establecidos en la gobernanza interna, todo ello, a partir de la óptica y dinámica comunitaria, respaldada desde el enfoque teórico de la comunalidad y la economía social, alcanzand o efectos ventajosos para el tejido social comunitario, orientado mediante el aprovechamiento controlado de su territorio y recursos, a partir del respeto, la solidaridad, imparcialidad y confianza en los procesos de organización laboral y gubernamental que administran las acciones comunitarias cotidianas, así como, aquellas que son elemento clave de los proyectos de emprendimiento turístico dirigidas a la producción y redistribución igualitaria de los beneficios conquistados por las tareas y proyectos que han implementado, como una opción para crear empleos, reducir la migración, transformar los espacios y escenarios en los que habitan, ampliar las oportunidades de ingreso, y, así, viabilizar un panorama social, cultural, económico y de perspectiva de vida más favorable, sobre las condiciones en las que durante años permanecieron, esto, sin olvidar su identidad, manifestaciones socioculturales, idiosincrasia y tradiciones originarias, con el propósito de lograr el desarrollo local en las comunidades rurales indígena

\section{Referencias}

[1] Flores, C. (2014). Turismo rural como factor de desarrollo local, desde La Perspectiva de la Comunalidad en una comunidad rural. El Alberto, Estado de Hidalgo. Revista Mexicana de Ciencias Agrícolas. (9). México.

[2] Coraggio J.L. (2003) La política social y economía del trabajo. Miño y Dávila/ Colegio Mexiquense A.C, Zinacantepec, México. 